\title{
Determinación de campos onomásticos en las bases de datos descriptivas de imagen en movi- miento
}

\author{
Jorge Caldera Serrano \\ María Victoria Nuño Moral \\ Felipe Zapico Alonso \\ Universidad de Extremadura
}

\subsection{Resumen}

Se muestra una propuesta de estructura y normalización de campos onomásticos para las bases de datos documentales del material audiovisual de las empresas televisivas. Se proponen campos para la identificación de personas físicas, personas jurídicas y entidades, ya sean visionadas o referenciadas en el documento audiovisual. Se definen dichos campos, se proporcionan notas sobre su alcance y utilización y se ofrecen diversos ejemplos.

Palabras clave: Archivos de televisión. Documentación audiovisual. Bases datos. Gestión documental. Puntos de acceso onomásticos.

\subsection{Abstract}

Proposal of a structure and control of personal name access points for visual, sound and audiovisual records in television documentation centres.

Keywords: Audiovisual archives. Audiovisual documentation. Databases. Information management. Personal name access points.

\section{Introducción}

La evolución de los medios de comunicación ha ido paralela a la transformación y avance de los medios técnicos. Por ello, y por la necesidad innata del hombre de comunicarse, el medio impreso fue el primero que se utilizó para la transmisión del conocimiento e hizo posible la distribución de la información a través de la imprenta y, posteriormente, de las rotativas. Pero la necesidad de información era y es cada vez mayor, por lo que hubo que adaptarse a diferentes inventos, tales como el telégrafo, el cual permitía la comunicación por medio de ondas. 
La radio fue uno de los grandes avances tecnológicos y al mismo tiempo, se convirtió en un medio de democratización de la información en nuestra sociedad. Pero, sin duda, la televisión logró convertir la idea de MacLuhan -la pertenencia a una aldea global, la existencia de una tribu televisiva - en una realidad, ya que en torno a dicho medio de comunicación se reúnen las familias tanto para acceder a la información como para entretenerse.

Los mass media se constituyen en grandes empresas que controlan y acceden a la información por medio de un método cercano al monopolio, ya que controlan tanto medios de información impresos como radiofónicos. Actualmente, la televisión es el medio en el cual se observan las luchas más encarnizadas entre las mismas. De hecho, se ha convertido en el núcleo mediático a controlar, tanto por su calado social como por sus elevadas cuotas de audiencias y, consiguientemente, por la importancia de los ingresos publicitarios que producen.

El cuarto poder accede, difunde y conserva gran cantidad de información, la cual se caracteriza por su dispersión temática y por su diversidad de formatos y soportes. Para el control de este importante activo empresarial, en casi todas las cadenas televisivas — en menor medida en las cadenas locales - se ha constituido un servicio de documentación que atiende a las necesidades informativas y formativas de sus periodistas, que son los encargados, en definitiva, de crear el patrimonio intelectual y cultural de la empresa. Dichos servicios documentales son vitales para las empresas audiovisuales; tanto es así que suelen estar integrados dentro de la propia redacción, y tanto su personal como la labor que desarrollan están, cada vez, más reconocidos. La estructura de estos servicios suele ser compleja y dispar. Las fórmulas concretas de organización dependen de la actividad desarrollada, así como de los tipos y soportes documentales. las unidades de documentación audiovisual, escrita y sonora son prácticamente imprescindibles en los servicios de información de las televisiones. Por el contario, las fototecas no siempre existen. Ahora bien, dicha división no es una cortapisa para otro tipo de organizaciones. Así, tal y como señala la literatura documental y periodística, en ocasiones se distinguen unidades dedicadas a los programas informativos y de entretenimiento por separado. Aunque esta división organizativa no está motivada en sí tanto por el tipo de programa como por la clara diferenciación del uso y demandas documentales.

\section{Las bases de datos de los archivos de televisión}

Los centros de documentación son el aspecto visible de un gran entramado documental en el que se conjugan las tipologías documentales, soportes y necesidades más dispares. En la correcta gestión documental y, muy especialmente, en el rápido acceso al material solicitado está jugando un papel fundamental el desarrollo de la informática. La informatización de las estructuras documentales es una

Scire. 8:1 (en.-jun. 2001) 147-156. 
realidad que sustenta un intercambio fluido de la información entre documentalistas y comunicólogos, y facilita que la información se conserve y esté accesible por medio de una serie de parámetros establecidos. De este pacto —en el que la comunicación y el entendimiento son imprescindibles- surgen las estructuras conceptuales de las bases de datos que albergarán la información como sustituto del documento original. Las bases de datos actuales han sido desarrolladas con criterios y filosofía analógicos (en cuanto al soporte); y aún existen graves problemas - tanto intelectuales como técnicos- para desarrollar herramientas documentales adecuadas a la nueva realidad. Tanto es así, que muchas cadenas que trabajan con material digital no han abordado una clara reconversión de su gestión documental. Actualmente, y en un futuro cercano, las bases de datos contarán con una serie de informaciones con las que a día de hoy parece imposible contar.

Realizando una división por áreas, señalamos los aspectos considerados hasta la fecha en las bases de datos:

1) Datos de control: Tanto del propio material — registro, fecha de entrada, nivel de análisis, etc. - como de la producción del documentalista.

2) Datos relativos a los aspectos físicos: Aunque la descripción física es uno de los aspectos que de manera más clara evoluciona con la digitalización, deberán consignarse aspectos relativos tanto al audio como al vídeo (banda imagen y banda sonido), así como sobre soportes, formatos y duración.

3) Titulares que identifican la información: Tanto títulos de los programas y de las noticias de los informativos como nombre de las series, reportajes y cualquier otro formato existente en televisión.

4) Descripción visual y sonora del material: Un aspecto que va a ser ampliamente modificado por el impacto de la digitalización será la descripción del plano, también llamado análisis cronológico, minutado, contenido, etc.

5) Descriptores temáticos: Descriptores que deben aludir claramente tanto a los aspectos visionados como referenciados en los documentos audiovisuales. La identificación temática es un aspecto especialmente importante al ser un método muy habitual de acceso a la información. Estos campos se confeccionan con herramientas documentales creadas ad hoc por las diferentes cadenas, siendo los tesauros los lenguajes documentales más usados. Existen también nuevas experiencias que han desarrollado instrumentos válidos a través de las clasificaciones facetadas.

6) Descriptores geográficos: Los que se identifican tanto lugares como aspectos geográficos visionados en el material, señalando tanto accidentes geográficos como ciudades, calles o edificios. 
7) Descriptores cronológicos: Estos campos identifican una serie de aspectos relativos a la data cronológica de la información y de las imágenes.

8) Datos de producción: Área en la cual se indican tanto la procedencia de la información como su potencial reutilización y explotación comercial legal.

9) Datos de emisión: Día y hora de emisión, ámbito de difusión, reemisiones, versiones e idiomas, etc. Cuestiones nada baladíes que deben ser controladas no sólo como fórmula de acceso sino como método de control de la información generada por la institución audiovisual.

10) Información de localización: Es importante que, una vez analizado el material, éste quede accesible para los usuarios, contando con el factor "rapidez". Los campos de localización que identifican las signaturas y los depósitos deben ser parte fundamental. La digitalización ofrece la posibilidad de contar con un único enlace para llegar a la información de una forma infinitamente más rápida.

11) Responsabilidad de la información: Conjunto de campos que identifican a los responsables de la creación de la pieza o programa audiovisual. Aunque su relación con los campos onomásticos es evidente —al indicar como responsables tanto a personas físicas como jurídicas-, no deben ser considerados como descriptores onomásticos sino como instrumento de control de la autoría intelectual de la información o programa.

\section{Campos onomásticos}

La identificación de los sujetos protagonistas de la información resulta absolutamente imprescindible a la vista de la reiterada solicitud de material audiovisual por parte de los usuarios. Esta tarea de identificación no resulta nada fácil, pues no existen herramientas audiovisuales ni tesauros icónicos que nos indiquen qué personaje tenemos en nuestros reproductores. Las referencias culturales y la experiencia profesional suelen ser los dos aspectos vitales para una correcta identificación de los personajes, junto con una actitud del investigador documental orientada a conseguir la información más completa posible.

Existe software en desarrollo que intenta identificar a los personajes referenciados tanto en la banda sonido como en la de vídeo. Sin embargo, este trabajo es actualmente realizado por el documentalista, y se precisan herramientas que aún están sin desarrollar completamente, y que en cualqueir caso exigirán tener al personaje en memoria y funcionarán tan solo cuando coincidan los rasgos físicos y en condiciones de iluminación, plano, movimiento de cámara, etc., adecuadas.

Los campos que se estima pueden integrarse en una base de datos audiovisual son los nueve siguientes: persona, plano persona, denotación de personas, entidad, plano entidad, denotación de entidad, autor, intérprete y colaboradores. Aunque se 
señalan los campos onomásticos con los que puede contar una base audiovisual, no se plantea la lista con pretensiones de validez universal. Sería un grave error el intentar elaborar una herramienta documental sin contar con la presencia, las necesidades e inquietudes de los periodistas. Por ello, los campos de dicha serie deberán ser valorados de forma individual, tomando una decisión sobre su pertinencia y oportunidad.

En las tablas que se desarrollan a continuación se aporta información sobre la definición y alcance de cada campo y sobre su utilización. Igualmente, se muestran una serie de directrices para la confección normalizada del punto de acceso tanto de personas físicas como jurídicas. Finalmente, se proporciona un conjunto de ejemplos que ilustran su elaboración.

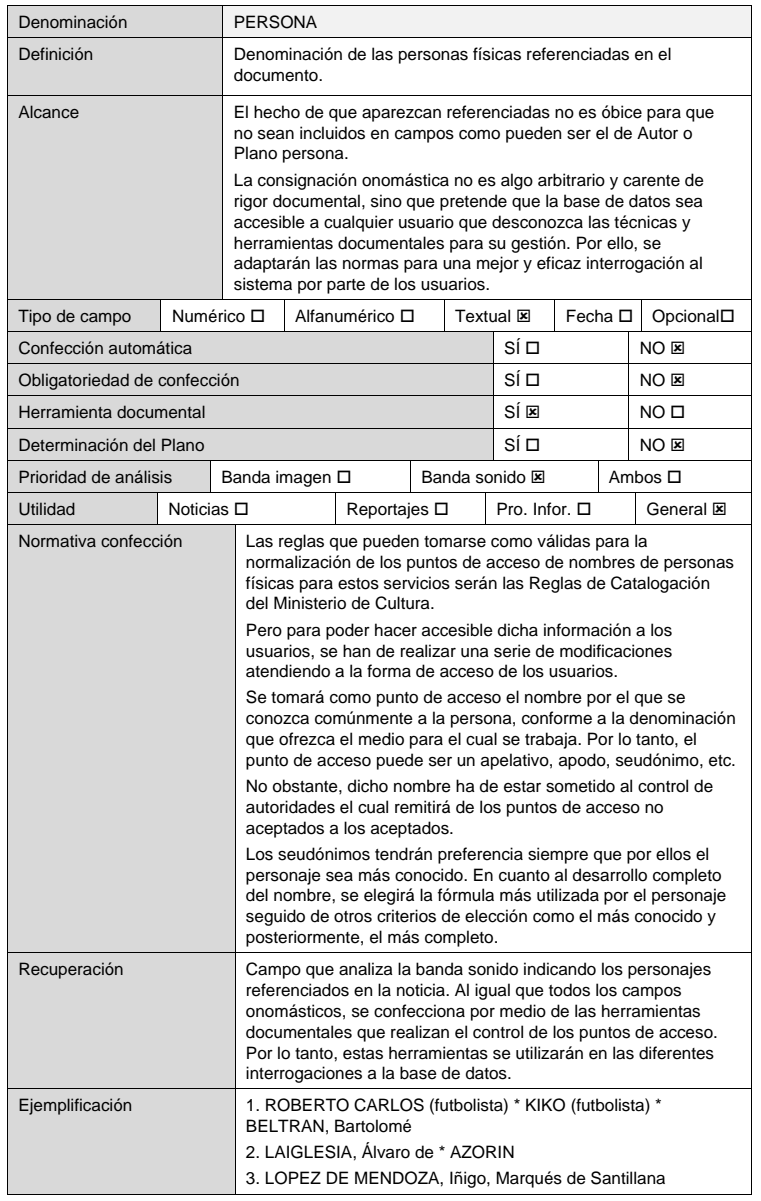

Tabla 1. Persona

Scire. 8: 1 (en.-jun. 2001) 147-156. 


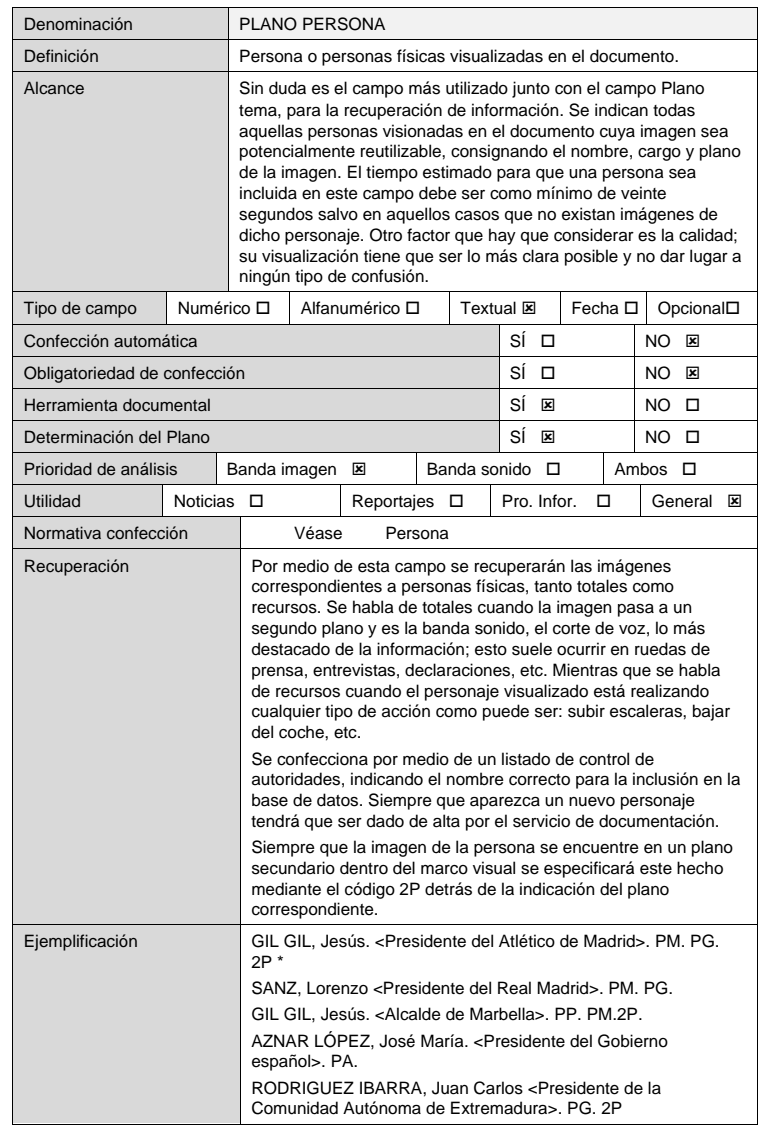

Tabla 2. Plano persona

Scire. $8: 1$ (en.-jun. 2001) 147-156. 


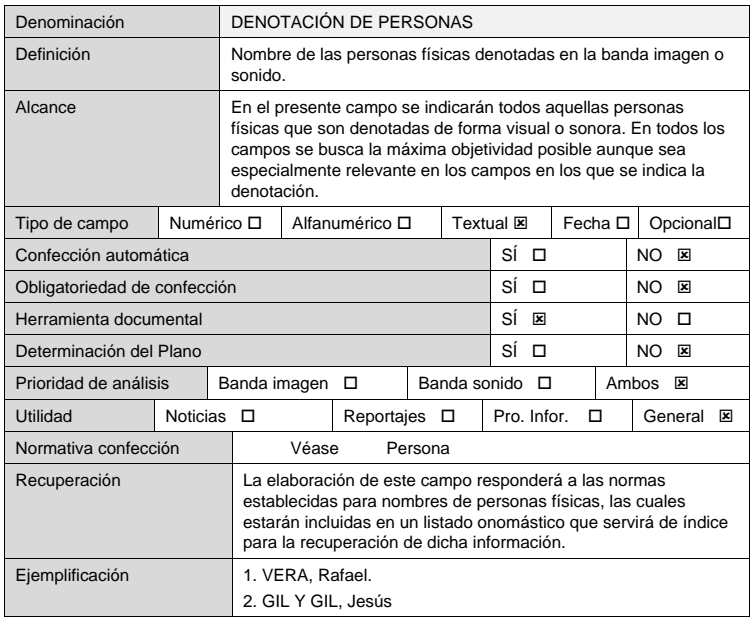

Tabla 3. Denotación de personas

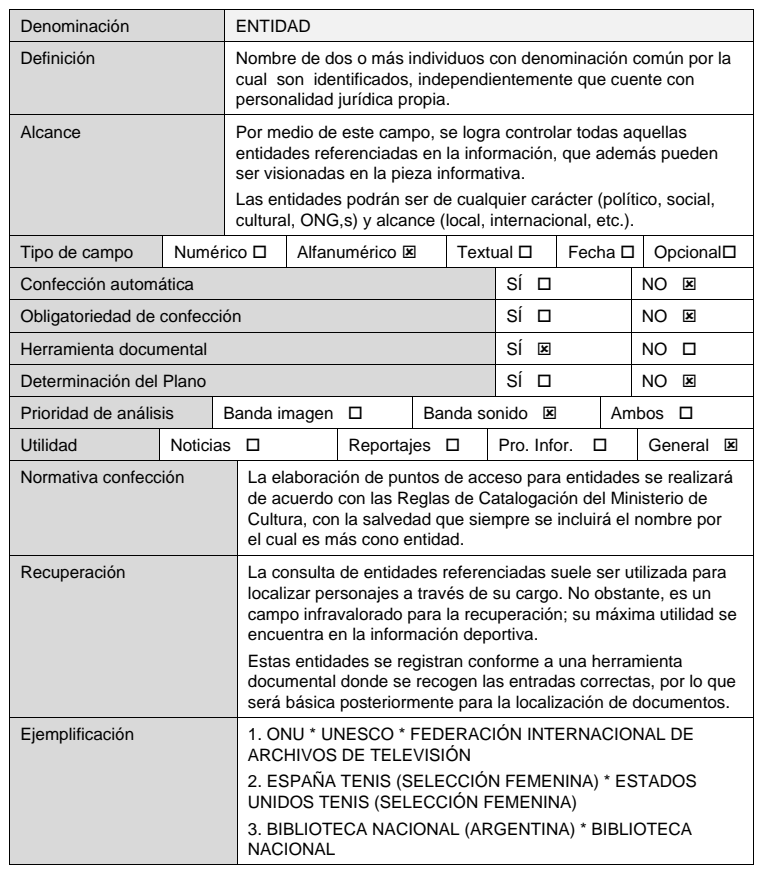

\section{Tabla 4. Entidad}

Scire. $8: 1$ (en.-jun. 2001) 147-156. 


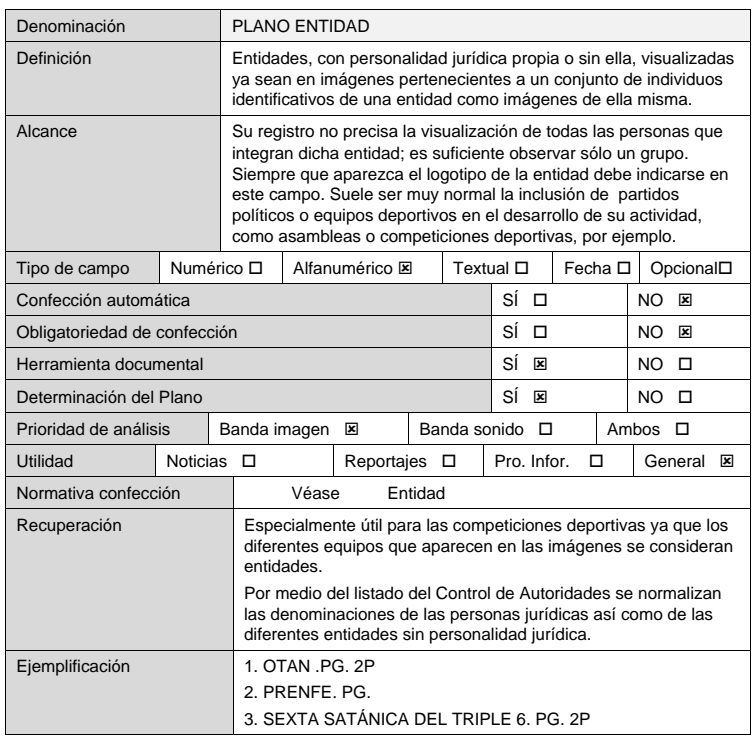

\section{Tabla 5. Plano entidad}

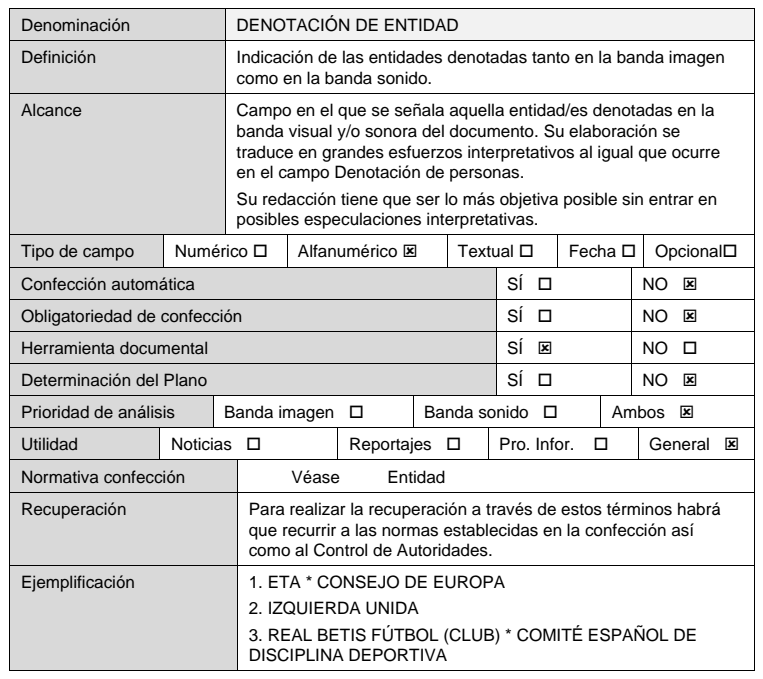

Tabla 6. Denotación de entidad

Scire. $8: 1$ (en.-jun. 2001) 147-156. 


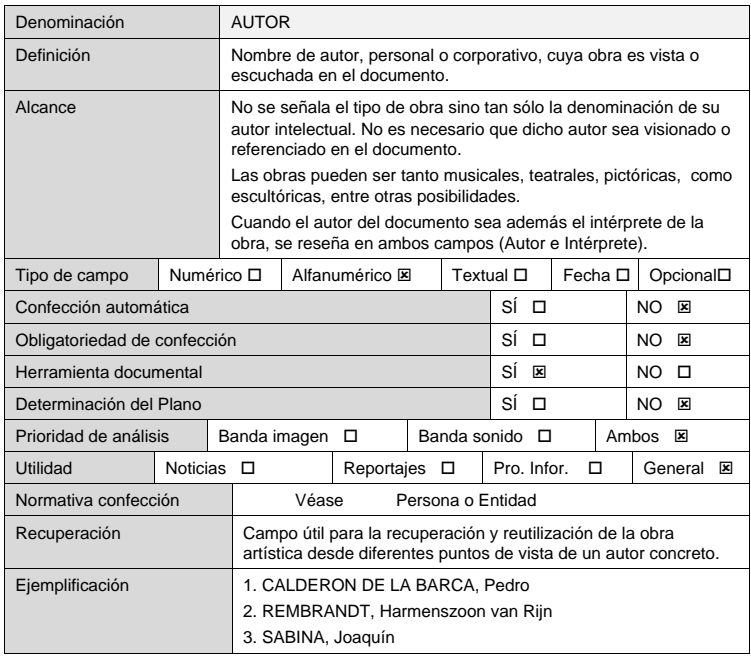

\section{Tabla 7. Autor}

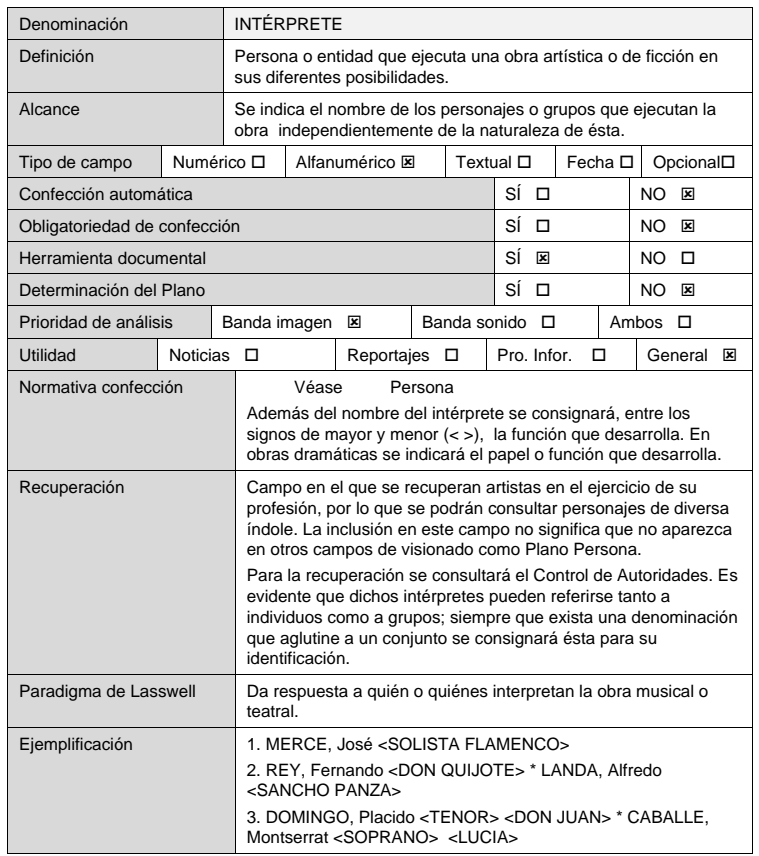

Tabla 8. Intérprete

Scire. 8: 1 (en.-jun. 2001) 147-156. 


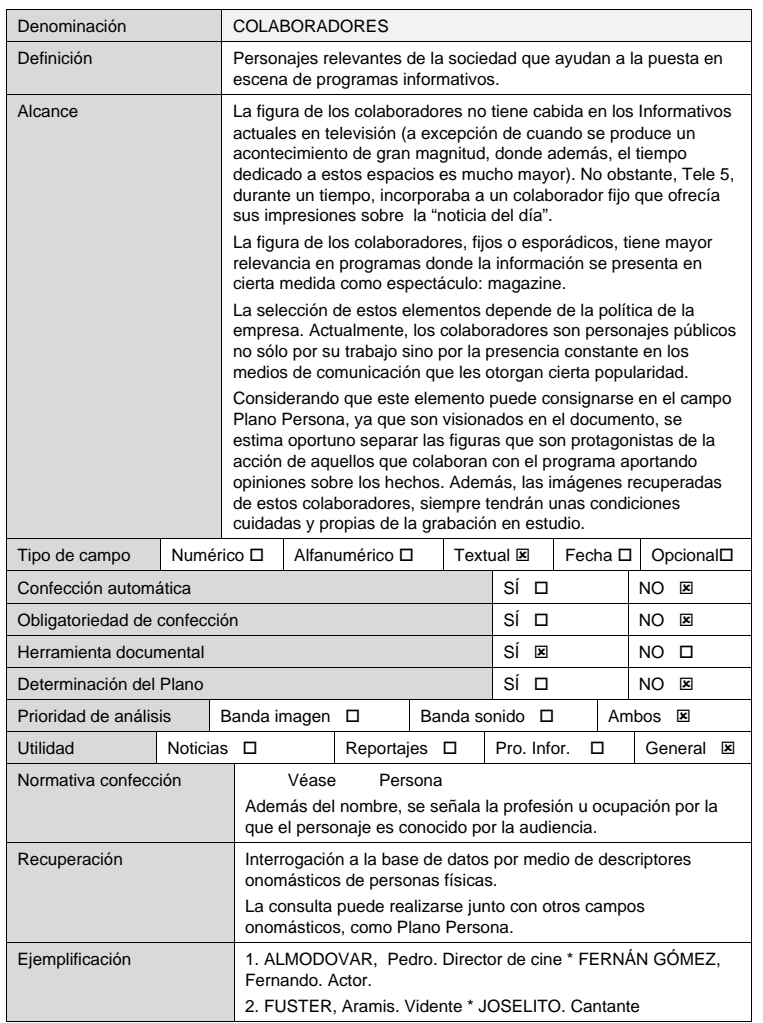

Tabla 8. Colaboradores

\section{Notas}

(1) Esta realidad está cambiando de una manera vertiginosa. Tal es así que, con el vertiginoso proceso de digitalización en las empresas audiovisuales, el registro documental no es un sustituto del documento descrito, sino un apoyo para conseguir el acceso. El problema de dicho proceso, que inicialmente sólo puede contar con aspectos positivos, es la rápida evolución que se nos exige a los departamentos de documentación para adaptarnos a realidades en constante evolución. 